\title{
Pulmonary function in histology technicians comp
with women from Michigan: effects of chronic low dose formaldehyde on a national sample of women
}

\author{
KAYE H KILBURN, R WARSHAW, J C THORNTON \\ From the Environmental Sciences Laboratory, University of Southern California School of Medicine, Los \\ Angeles, California 90033, and Workers Disease Detection Services, San Dimas, California 91773, USA
}

ABSTRACT Chronic workplace exposure to formaldehyde and solvents at low doses reduced pulmonary function in 280 non-smoker white women working as histology technicians. They were, studied during national workshops at four United States cities for four years. Height and age adjustedo comparisons of pulmonary function were made with women in a stratified random population sampleøo of Michigan and with a selected subset of the population that was used to model predictive pulmonary? equations for function. The major functional change in histology technicians was a steeper decrement in vital capacity and flows from age 20 to 60 by regression analysis than occurred in the modelled Michigan population. Furthermore non-smoking and currently smoking women studied at two sites had significantly lower flows than were found in the sample of Michigan women. There was now consistent effect of an aerosol bronchodilator on flows of women at the four sites. Diffusing capacity for carbon monoxide single breath and alveolar volume were below the comparison group ofo Michigan women only when tested at Washington DC.

Formaldehyde (HCHO) is a pungent and chemically reactive gas heavily used in many industries which is also a component of cigarette smoke and diesel exhaust. It is found frequently in indoor and outdoor air. It causes cancer in the nasal passages and lungs of rodents ${ }^{1}$ and may be a human carcinogen for these respiratory tissues. ${ }^{23}$ Controversy surrounds its acute and chronic effects on the function of the respiratory system. On the one hand, occupational formalin asthma has been described in renal haemodialysis nurses ${ }^{4}$ and pathologists. ${ }^{5}$ Five of 28 members of a haemodialysis unit staff had attacks of wheezing lasting for 10 hours to 10 days. ${ }^{6}$ Some subjects have responded to bronchial provocation, ${ }^{6}$ others have not. $^{7}$

Investigation of 230 suspected cases of asthma due to HCHO in Finland produced $12(5 \%)$ with typical symptoms responsive to bronchial provocation of $2 \cdot 5$ $\mathrm{mg} / \mathrm{m}^{3}{ }^{8}$ Thus it is not surprising that 15 asthmatic volunteers, naive for formaldehyde, when challenged with it lowered their threshold to methacholine challenge but showed no measurable acute effect on pulmonary function. ${ }^{9}$ They included 12 subjects with occupational $\mathrm{HCHO}$ asthma,${ }^{8}$ workers making acrylic

Accepted 18 July 1988 wool filters impregnated with phenol-formaldehydeon resin $^{10}$ and those making fibreglass batts similarly impregnated. ${ }^{11}$ Three groups of subjects studied before exposure were not significantly below predicted levels for FVC, $\mathrm{FEV}_{1}$, and $\mathrm{FEF}_{25-75}$. Cigarette smokers in the last group had significant cross shift decrements in these functions and in diffusing capacity, althougho non-smokers did not decrease. Since the type and magnitude of chronic effects of formaldehyde on pulmonary function were unresolved by these studies we studied female histology technicians for chronic effects by comparing them with a stratified random population sample of Michigan women. ${ }^{12} 13$

\section{Methods}

Volunteers were recruited from attendees of four national conventions of the National Society of Histotechnology. In the first cross sectional study inc Boston in 1982 spirometry was measured in 260 of $625^{\circ}$ women who attended. In Anaheim in 1983, 208 of 6440 women were studied by spirometry and in Washington in 1985,131 of 585 were similarly studied. At Little? Rock in 1986, 137 of 570 attending were studied. It was? decided to consider only those studied initially at each site in analysis (table 1) to avoid a training bias? Because our recruitment was directed at neuro- -2 
Table 1 Pulmonary function in non-retested white women who had never smoked when attending national conventions in Boston 1982, Anaheim 1983, Washington 1985, and Little Rock 1986 as percentage predicted (\%p) of Michigan women

\begin{tabular}{|c|c|c|c|c|c|c|c|c|}
\hline \multirow[b]{2}{*}{ Year } & \multicolumn{2}{|l|}{ Boston } & \multicolumn{2}{|l|}{ Anaheim } & \multicolumn{2}{|c|}{ Washington } & \multicolumn{2}{|c|}{ Little Rock } \\
\hline & 1982 & $\% p$ & 1983 & $\% p$ & 1985 & $\% p$ & 1986 & $\% p$ \\
\hline 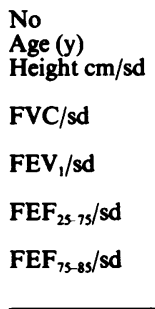 & $\begin{array}{l}77 \\
39 \\
162.6 \\
\pm 7.47 \\
3.650 \\
\pm 0.620 \\
3.045 \\
\pm 0.579 \\
3 \cdot 186 \\
\pm 1.031 \\
1 \cdot 100 \\
\pm 0.704\end{array}$ & $\begin{array}{l}(100 \cdot 5) \\
(101 \cdot 1) \\
(105 \cdot 1) \\
(111 \cdot 4)\end{array}$ & $\begin{array}{l}60 \\
38 \cdot 6 \\
163.1 \\
\pm 6.88 \\
3.630 \\
\pm 0.507 \\
2.956 \\
\pm 0.446 \\
2.920 \\
\pm 0.896 \\
0.861 \\
\pm 0.519\end{array}$ & $\begin{array}{l}(99 \cdot 6) \\
(97 \cdot 9)^{*} \\
(96 \cdot 0)^{*} \\
(86 \cdot 2)^{*}\end{array}$ & $\begin{array}{l}35 \\
37.7 \\
164 \cdot 1 \\
\pm 7.80 \\
3.826 \\
\pm 0.427 \\
3.202 \\
\pm 0.425 \\
2.926 \\
\pm 0.770 \\
0.967 \\
\pm 0.603\end{array}$ & $\begin{array}{l}(103.0) \\
(104.4) \\
(94.5)^{*} \\
(98.5)\end{array}$ & $\begin{array}{l}62 \\
39.9 \\
163.9 \\
\pm 5.69 \\
3.600 \\
\pm 0 \cdot 598 \\
3.015 \\
\pm 0.544 \\
3 \cdot 192 \\
\pm 1.096 \\
0.932 \\
\pm 0.499\end{array}$ & $\begin{array}{l}(98 \cdot 2) \\
(99 \cdot 8) \\
(106 \cdot 2) \\
(96 \cdot 7)\end{array}$ \\
\hline
\end{tabular}

* $p<0.05$

behavioral symptoms and testing a biased selection for pulmonary function testing seems unlikely. For table 2 , all non-smoking white women studied in Boston, the initial site, were considered and for table 3, the attendees at Washington and Little Rock who had not been studied previously were analysed. Only slight variability for mean values for pulmonary function was noted between sites (table 1). For regression analysis of spirometry $v$ age we used the largest sample of histology technicians who were thus uncomplicated and also the first group studied.

Technicians completed symptom indices and medical history and exposure questionnaires and had pulmonary and neurobehavioral testing. Only methods relevant to this paper will be described. Because environmental sampling of each laboratory from which a participating histology technician came would be a mammoth nationwide task we elected to sample exposure to formaldehyde and solvents in 10 laboratories within the Los Angeles area. Area sampling was done for formaldehyde, xylene, toluene, and chloroform for one to four hours by the regional NIOSH laboratory using sorbent tubes for $\mathrm{HCHO}$ and impingers for solvents and analysed by gas chromatography. For all four agents the levels varied widely: therefore only ranges are given. Mean one to four hour $\mathrm{HCHO}$ concentrations in specimen preparation and sampling areas were from 0.2 to $1.9 \mathrm{ppm}$ with peaks to $5 \mathrm{ppm}$. In the rooms containing tissue processors xylene ranged from 8.9 to $12.6 \mathrm{ppm}$ and chloroform varied from 2 to $19 \cdot 1 \mathrm{ppm}$. In staining and cover slipping operations xylene was from $3 \cdot 2$ to 102 $\mathrm{ppm}$ and toluene was from 8.9 to $12.6 \mathrm{ppm}$. These wide variations in concentrations were explained by the

Table $2 F E V_{1}$ and $F E F_{25-75}$ in 97 non-smoking white women compared with Michigan women

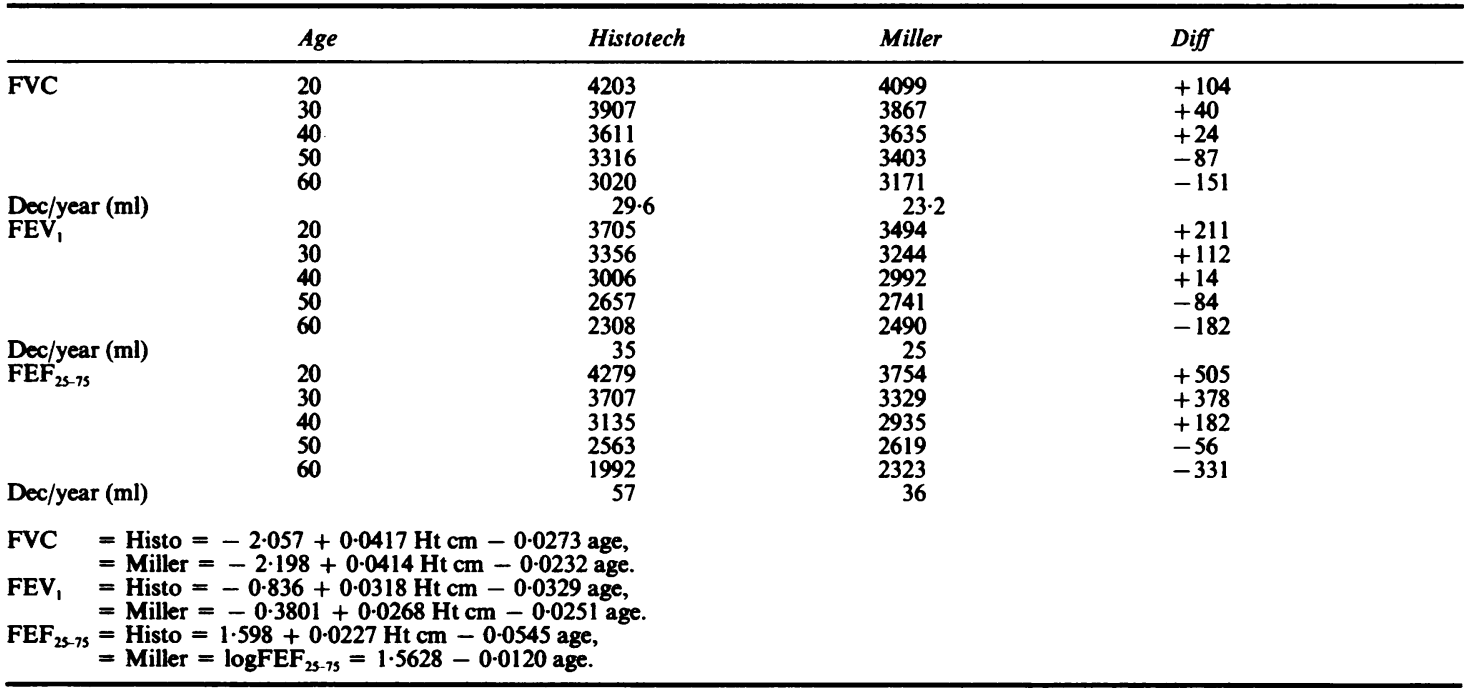


Table 3 Comparison of histology technicians studied at Little Rock and Washington with all Michigan white women by neverz smoked and currently smoking ${ }^{1213}$

\begin{tabular}{|c|c|c|c|c|c|}
\hline & \multicolumn{2}{|l|}{ Never smoked } & \multicolumn{2}{|c|}{ Currently smoking } & $\overline{\bar{A}}$ \\
\hline & L Rock (60) & Wash (70) & L Rock (22) & Wash (14) & \\
\hline 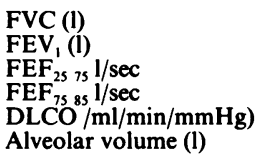 & $\begin{array}{l}-0.19^{*} \\
-0.11^{*} \\
-0.02^{*} \\
-0 \cdot 17^{*} \\
-0.49 \\
-0.01\end{array}$ & $\begin{array}{l}-0.03 \\
0.00 \\
-0.11^{*} \\
-0.27^{*} \\
-3.15^{*} \\
-0.05\end{array}$ & $\begin{array}{l}-0 \cdot 20^{*} \\
-0 \cdot 24^{*} \\
-0 \cdot 20^{*} \\
-0 \cdot 50^{*} \\
-1 \cdot 21 \\
-0.13\end{array}$ & $\begin{array}{l}0.02 \\
-0.10 \\
-0.33^{*} \\
-0.67^{*} \\
-0.74 \\
0.00\end{array}$ & $\begin{array}{l}\overline{\bar{D}} \\
\bar{\Phi} \\
\varrho \\
\varrho \\
\stackrel{0}{0}\end{array}$ \\
\hline
\end{tabular}

variety of mixtures of solvents used, diversity of activities, and large variations in ventilation within and between laboratories.

Spirometric measurements were obtained with rolling seal (waterless) spirometers with subjects standing and using a nose clip following ATS Snowbird recommendations. ${ }^{14}$ Subjects were carefully instructed and encouraged to achieve maximal inspiration and to expire fully. Three or more forced expiratory efforts from full inspiration were recorded and the best two required to agree within $5 \%$. DLCO and alveolar volume single breath were measured with carbon monoxide during a 10 second breathhold by the method of Ogilvie et $a l^{15}$ as modified by Miller et al. ${ }^{13}$

Statistical analyses are based on white women. Statistical calculations, including regression analysis, were performed with a Hewlett-Packard 9816 microcomputer using the HP statistical library. Analysis of variance using the PC SAS statistical program in an IBM computer compared function values for white female histology technicians with the entire sample of Michigan women. This probability sample of a large 9000000 population industrial state was initially constructed via random choice of residential telephone numbers as controls to subjects on farms quarantined for polybrominated biphenyls. An adult and child from each selected household was invited for study, contacted, scheduled for examination at one of six Michigan sites, and studied in detail in 1978. Approximately $42 \%$ of those originally invited had pulmonary functions measured from which normal values were developed using the 235 considered normal on the basis of medical history and examination. For futher details of the selection process see Miller $e t$ $a l .{ }^{12}{ }^{13}$ The entire Michigan sample of 486 white women which provided a representative sample of women in the United States was compared with white women in this paper. It appeared reasonable to compare them with a representative population for evidence of an occupational exposure rather than with a hand picked normal group selected for modelling.

What this meant was that we restored to the group used for "normal" predictive pulmonary function modelling ${ }^{1213}$ those excluded because of clinical abnor-o malities. Subjects returned to the Michigan popula- $-\frac{1}{3}$ tion sample for these analyses included those withs chronic cough with phlegm, asthma, wheezing, dysp-? noa, angina pectoris, and hypertension or with ai diagnosis of chronic bronchitis, emphysema, tuber-o culosis, pneumoconiosis, and coronary heart disease응 Thus the comparison group included all adult womenstudied in Michigan. A p value of $<0.05$ was used tof demonstrate significance. They were compared smok ing specific to 70 non-smoking women studied ate Washington, DC, 60 at Little Rock, Arkansas, and $14^{\circ}$ and 22 current smokers at the respective sites Individual percentages of predicted were calculatedo for each measurement and averaged for each measurement by site.

\section{Results}

A total of 280 white women who had never smoked cigarettes were studied at the four sites from 1982 to 1986. Forty were restudied and 240 were studied only? once. The mean ages of yearly groups were 37.6 to 39.90 years and mean height of 162.6 to $165.3 \mathrm{~cm}$ (table 1). When the 77 non-smoking women in the 1982 groups studied in Boston were compared with normal women in Michigan, these women had almost identical meano FVC, $\mathrm{FEV}_{1}$, and flows which slightly exceeded $100 \%$ of predicted (table 1). The same comparisons, 음 however, for the 1983 group of 60 women who have never smoked in Anaheim, which is in the Los Angeles으. basin, showed that mean $F_{1} V_{1}$ and flows were decreased compared with Michigan values and the $e^{r}$ values were substantially decreased compared with the $\sim$ members of the group studied in Boston. These ${ }_{\mathbb{E}}$ differences (table 2 ) were $0.4 \%$ for vital capacity, $3 \cdot 2 \% 0$ for $\mathrm{FEV}_{1}, 9 \cdot 1 \%$ for midflow, and $15 \cdot 2 \%$ for terminato flow. The 1985 study in Washington once again showed mean FVC and FEV above the Michigan $\stackrel{?}{\rightarrow}$ women population values and considerably above the $\square$ Anaheim levels. Flow FEF $_{25-75}$ that was $94.5 \%$ of the Michigan value differed from Anaheim. Study of the group in 1986 in Little Rock showed that mean FVC 
and $F E V_{1}$ resembled earlier studies and were near the Michigan values, but flows returned to Boston levels compared with Michigan levels at $106 \cdot 2 \%$ of midflow and $96.7 \%$ for terminal flow.

None of the mean values differed significantly from those for the modelled population from Michigan. The entire group tested at each site was used to develop regression equations. The first step was to base regression equations for this group on the 106 Boston female non-smokers (table 2). This permitted estimates to be made of the effect of age and height on FVC, $F_{1}$, and flows for subjects in each decade to compare with Michigan predicted values. The histotech predictive equations for FVC, $\mathrm{FEV}_{1}$, and $\mathrm{FEF}_{25-75}$ produced higher values in the younger ages and low values after age 40 . In effect, the values for histotechs were higher at age 20 and cross the Michigan population values because their calculated age decrement coefficients were greater (figure).

The second analytical step was to compare the pulmonary function values measured at Washington and Little Rock for women who had never smoked and for current smokers with the corresponding values from the Michigan population study. This population cross comparison (table 3) showed that the non-smoking histology technicians at Washington and Little Rock as groups, corrected for age and height, had lower flows than the corresponding stratified random sample of Michigan women. The Little Rock test group also had significantly lower FVC, FEV , and flows whereas $\mathrm{DLCO}_{\mathrm{sb}}$ was significantly lower only in the women who had never smoked who were studied in Washington.

The current cigarette smokers group when adjusted for effects of smoking, based on the Michigan

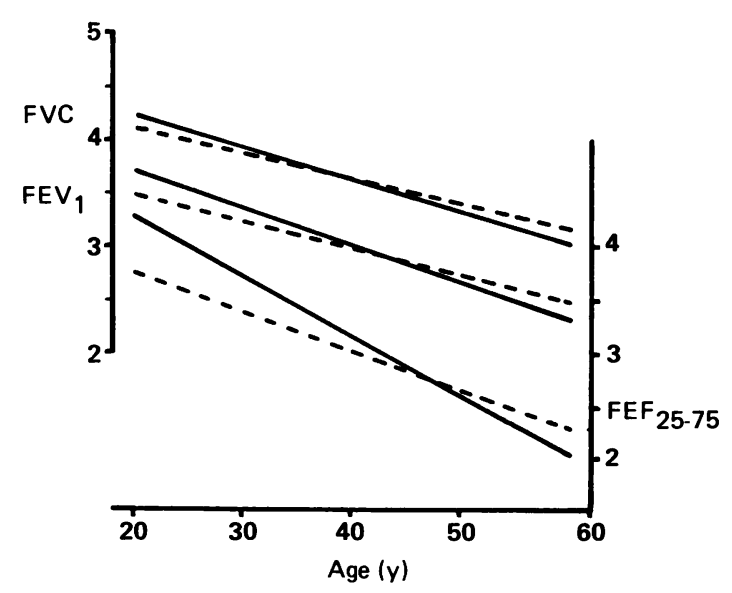

Age related decrements in FVC and FEV (1) and for $F E F_{25-75}(l / s)$ (mid-flow) plotted for female histology technicians compared with-- - reference population. ${ }^{12}$ studies, ${ }^{12} 13$ showed identical changes to the neversmokers in Little Rock and differed from those who had never smoked in Washington only in that the difference for $\mathrm{DLCO}_{\mathrm{sb}}$ was not significant.

\section{Discussion}

The pulmonary function measurements for histology technicians sampled from their national population four times across five years did not vary in a systematic or statistically significant way from year to year. Although different individuals were studied each year, as repeated samples of a national population, they behaved similarly and thus predictably each time. This observation provides assurance in ascribing significance to differences across time and site. Two major conclusions are suggested by these observations. The first is that this population appears to have better function than the comparison population from Michigan at age 20 but has greater decrements with time, resulting in lower function values at age 60 . Sampling the population at the mean age of 40 each year minimised the apparent differences because the histology technicians regression lines cross the Michigan womens regression lines near age 40. A second comparison by analysis of variance showed that histology technicians have significantly lower flows, although again the differences are small.

These complementary analyses of large groups suggest that there is a low magnitude chronic reduction of pulmonary function by formaldehyde which may be contributed to by solvent exposure. This reduction is not predicted from cross shift decreases which are not found (unpublished observations) except in asthmatics ${ }^{8}$ or in some cigarette smokers. ${ }^{11}$ In effect, we have shown a long term low magnitude decrement that occurs without a positive workplace challenge. The apparent reduction in function charted in Anaheim was not repeated. It may be related to exposure of Los Angeles basin air pollution and is being studied.

\section{References}

1 Swenberg JA, Kerns WD, Mitchell RI, Gralla EJ, Pavkov EL. Induction of squamous cell carcinomas of the rat nasal cavity by inhalation exposure to formaldehyde vapor. Cancer Res 1980;40:3398-401.

2 Liebling T, Rosenman KD, Pastides H, Griffith RG, Lemeshow S. Cancer mortality among workers exposed to formaldehyde. Am J Ind Med 1984;5:423-8.

3 Olsen JH, Asnaes S. Formaldehyde and the risk of squamous cell carcinoma of the sinonasal cavities. Br J Ind Med 1986;43: 769-74.

4 Hendrick DJ, Lane DJ. Formalin asthma in hospital staff. Br Med J 1975;i:607-8.

5 Porter JAH. Acute respiratory distress following formalin inhalation. Lancet 1975;ii:603-4. 
6 Hendrick DJ, Lane DJ. Occupational formalin asthma. Br J Ind Med 1977;34:11-8.

7 Frigas E, Filley WV, Reed CE. Bronchial challenge with formaldehyde gas: lack of bronchoconstriction in 13 patients suspected of having formaldehyde-induced asthma. Mayo Clinic Proceedings 1984;59:295-9.

8 Nordman H, Keskinen H, Tuppurainen M. Formaldehyde asthma-rare or overlooked? $J$ Allergy Clin Immunol 1985;75:91-9.

9 Witek TJ, Schachter EN, Tosun T, Beck GJ, Leaderer BP. An evaluation of respiratory effects following exposure to $2.0 \mathrm{ppm}$ formaldehyde in asthmatics: lung function, symptoms and airway reactivity. Arch Environ Health 1987;42:230-7.

10 Schoenberg JB, Mitchell CA. Airway disease caused by phenolic (phenol-formaldehyde) resin exposure. Arch Environ Health 1975;30:574-77.

11 Kilburn KH, Warshaw R, Boylen CT, et al. Pulmonary and
Kilburn, Warshaw, Thornton

neurobehavioural effects of formaldehyde exposure. Arch Environ Health 1985;40:254-60.

12 Miller A, Thornton JC, Warshaw R, Bernstein J, Selikoff IJ Teirstein AS. Mean and instantaneous expiratory flows, FVC: and $F E V_{1}$ : prediction equations from a probability sample of Michigan, a large industrial state. Bull Eur Physiopathol Respir 1986;22:589-97.

13 Miller A, Thornton JC, Warshaw R, Anderson H, Teirstein AS Selikoff. Single breath diffusing capacity in a representative sample of the population of Michigan, a large industrial state. $\mathrm{D}$ Am Rev Respir Dis 1983;127:270-7.

14 ATS Statement. Snowbird workshop on standardization of ș spirometry. Am Rev Respir Dis 1979;119:831-8.

15 Ogilvie CM, Forster RE, Blakemore WS, Morton JW. $\mathrm{A}^{\vec{\circ}}$ standardized breath holding technique for the clinical $\angle$ measurement of the diffusing capacity for carbon monoxide. Clin Invest 1957;36:1-17.

\section{Vancouver style}

All manuscripts submitted to the $\mathrm{Br} J$ Ind $\mathrm{Med}$ should conform to the uniform requirements for manuscripts submitted to biomedical journals (known as the Vancouver style)

The $\mathrm{Br} J$ Ind Med, together with many other international biomedical journals, has agreed to accept articles prepared in accordance with the Vancouver style. The style (described in full in Br Med J, 24 February 1979, p 532) is intended to standardise requirements for authors.

References should be numbered consecutively in the order in which they are first mentioned in the text by Arabic numerals above the line on each occasion the reference is cited (Manson ${ }^{1}$ confirmed other reports $\left.{ }^{2-5} \ldots\right)$. In future references to papers submitted to the $\mathrm{Br} J$ Ind Med should include: the names of all authors if there are six or less or, if there are more, the first three followed by et al; the title of journal articles or book chapters; the titles of journals abbreviated according to the style of Index Medicus; and the first and final page numbers of the article or chapter.

Examples of common forms of references are:

1 International Steering Committee of Medical Editors. Uniform requirements for manuscripts submitted to biomedical journals. Br Med J 1979;1:532-5.

2 Soter NA, Wasserman SI, Austen KF. Cold urticaria: release into the circulation of histamine and eosino-phil chemotactic factor of anaphylaxis during cold challenge. $N$ Engl J Med 1976;294:687-90.

3 Weinstein L, Swartz MN. Pathogenic properties of invading micro-organisms. In: Sodeman WA Jr, Sodeman WA, eds. Pathologic physiology: mechanisms of disease. Philadelphia: W B Saunders, 1974:457-72. 